\title{
Regulating cell fate of human amnion epithelial cells using natural compounds: an example of enhanced neural and pigment differentiation by 3,4,5-tri-O-caffeoylquinic acid
}

\author{
Meriem Bejaoui ${ }^{1,2}$, Farhana Ferdousi ${ }^{1,2,3}$, Yun-Wen Zheng ${ }^{2,4}$, Tatsuya Oda ${ }^{2,4}$ and Hiroko Isoda 1,2,3*
}

\begin{abstract}
Over the past years, Human Amnion Epithelial Cells (hAECs), a placental stem cell, are gaining higher attention from the scientific community as they showed several advantages over other types of stem cells, including availability, easy accessibility, reduced rejection rate, non-tumorigenicity, and minimal legal constraint. Recently, natural compounds are used to stimulate stem cell differentiation and proliferation and to enhance their disease-treating potential. A polyphenolic compound 3,4,5-Tri-O-Caffeoylquinic Acid (TCQA) has been previously reported to induce human neural stem cell differentiation and may affect melanocyte stem cell differentiation as well. In this study, TCQA was tested on 3D cultured hAECs after seven days of treatment, and then, microarray gene expression profiling was conducted of TCQA-treated and untreated control cells on day 0 and day 7. Analyses revealed that TCQA treatment significantly enriched pigment and neural cells sets; besides, genes linked with neurogenesis, oxidation-reduction process, epidermal development, and metabolism were positively regulated. Interestingly, TCQA stimulated cell cycle arrest-related pathways and differentiation signaling. On the other hand, TCQA decreased interleukins and cytokines expression and this due to its anti-inflammatory properties as a polyphenolic compound. Results were validated to highlight the main activities of TCQA on hAECs, including differentiation, cell cycle arrest, and anti-inflammatory. This study highlights the important role of hAECs in regenerative medicine and the use of natural compounds to regulate their fate.
\end{abstract}

Keywords: 3,4,5-tri-O-caffeoylquinic acid (TCQA), Human amniotic epithelial stem cells (hAECs), Cell cycle arrest, Differentiation, Pigment cell, Neurogenesis, Inflammation

\section{Introduction}

Finding a reliable, effective, and safe source of stem cells to treat various incurable diseases constitute one of the most important challenges of regenerative medicine in this modern society [1]. Broadly, stem cells are classified into embryonic and adult stem cells. Embryonic Stem Cells (ESCs) can differentiate into various types of precursor cells for the regeneration of damaged tissue, as for

\footnotetext{
*Correspondence: isoda.hiroko.ga@u.tsukuba.ac.jp

${ }^{3}$ Faculty of Life and Environmental Sciences, University of Tsukuba, 1-1-1 Tennodai, Tsukuba, Ibaraki 305-8572, Japan

Full list of author information is available at the end of the article
}

adult stem cells like Mesenchymal Stem Cells (MSCs), they are widely used in repairing and maintaining the tissue that were isolated from [2]. However, both sources of stem cells have limitations in clinical practice, present ethical and legal issues, spontaneous differentiation, difficulty of extraction, and tumorigenicity $[3,4]$.

In recent years, attention was given to cells derived from discarded placenta, as they are emerging as a novel alternate source of pluripotent and multipotent stem cells. The amniotic membrane, which forms the innermost layer of the fetal membrane, is of particular interest. Two types of stem cells can be derived from the human amniotic membrane: the Human Amniotic Mesenchymal original author(s) and the source, provide a link to the Creative Commons licence, and indicate if changes were made. The images or other third party material in this article are included in the article's Creative Commons licence, unless indicated otherwise in a credit line to the material. If material is not included in the article's Creative Commons licence and your intended use is not permitted by statutory regulation or exceeds the permitted use, you will need to obtain permission directly from the copyright holder. To view a copy of this licence, visit http://creativecommons.org/licenses/by/4.0/. The Creative Commons Public Domain Dedication waiver (http://creativeco mmons.org/publicdomain/zero/1.0/) applies to the data made available in this article, unless otherwise stated in a credit line to the data. 
Stromal Cells (hAMSCs) and the Human Amniotic Epithelial Cells (hAECs) [5, 6]. The hAECs have been reported to have properties similar to both ESCs and MSCs because of their ability to differentiate into verious types of cells generated from all three germ layers, and to expand in culture $[7,8]$. Most importantly and in contrast to ESCs, and MSCs, hAECs do not form teratomas in vivo, have low immunogenicity, are non-tumorigenic when transplanted, are obtained with non-invasive procedure, and have minimal ethical and legal barriers [1]. Additionally, these cells are gaining a huge interest among the stem cell research community because they are able to differentiate into a broad spectrum of cell types such as neuronal, epithelial, adipocyte, pancreatic, cardiac, osteogenic, and hepatic cells [9-11]. Moreover, hAECs have anti-inflammatory, wound healing, and immunomodulatory properties, as well as promoting re-epithelization and inhibiting angiogenesis. These beneficial activities of hAECs have contributed to their potential use in clinical trials $[12,13]$.

Currently, substances like synthetic cytokines and proteins and recombinant growth factors are used to induce stem cell differentiation. However, several side effects were observed including, toxicity, malignancy, and a high risk of rejection. Moreover, these molecules degrade rapidly and need constant replacement, which makes the process costly and limits the use $[14,15]$. In this context, finding new molecules to act on stem cell fate has become one of the biggest challenges within the scientific community. Recently, the use of plant-based natural products that may affect the differentiation of stem cells has been approved in the mainstream of medicine because of their high availability, minimum toxicity, and low secondary effects $[16,17]$. It has been reported that different natural compounds may regulate early biological events in hAECs to induce directed differentiation such as rosmarinic acid induced neuronal differentiation, whereas isorhamnetin induced hepatic-lineage specific differentiation in hAECs $[18,19]$. Also, verbenalin-treated hAECs revealed a therapeutic potential for Alzheimer's disease [20].

Caffeoylquinic Acid (CQA) and its derivatives are polyphenolic compounds found in a variety of plants and exhibited several activities including antioxidant, antibacterial, anticancer, antihistaminic, and pigmentationregulating effects [21-27].We distinguish as one of CQA derivatives, 3,4,5-Tri-O-Caffeoylquinic Acid (TCQA) with an IUPAC name (3R,5R)-3,4,5-tris[[(E)-3-(3,4-dihydroxyphenyl)prop-2-enoyl] oxy]-1-hydroxycyclohexane1-carboxylic. Previously, this compound was reported to inhibit aldose reductase, and to prevent hypertension, hyperglycemia, and Alzheimer's disease [28]. TCQA was found to enhance Adenosine Triphosphate (ATP) production in human neuroblastoma SH-SY5Y cell, and to improve deficit of learning and memory in the aging model Senescence-Accelerated Prone Eight (SAMP8) mice $[29,30]$. Moreover, in our previous studies, we demonstrated that TCQA promoted hair regrowth and pigmentation in eight-weeks-old $\mathrm{C} 3 \mathrm{H}$ male, human dermal papilla cells and human melanocytes via the upregulation of Wnt/ $\beta$-catenin pathway and its target genes. TCQA upregulated pathways involved in skin and hair stem cell differentiation and the protein expression of CD34, known to be enhanced when melanocytes stem cells are differentiating [31-33]. On the other hand, TCQA triggered the differentiation of Human Neural Stem Cells (hNSC) via Bone Morphogenetic Protein (BMP) pathway and the induction of cell cycle arrest [27]. Interestingly, the melanocytes are originally from the neural crest cells before they migrate and colonize the skin and the hair follicle. Their differentiation is induced by various pathways, including Notch, BMP, and Wnt/B-catenin pathways, which have been reported to be regulated by TCQA in vivo and in vitro [33, 34].

Taken together, TCQA is a potential candidate to induce stem cell differentiation into neuronal and pigment cell lineage. In this current research, the effect of TCQA on the activation of hAECs differentiation was investigated. Global gene expression profiling using DNA microarray showed the upregulation of genes significant in pigment and neuronal cell differentiation, neurogenesis, ATP process, inflammation, and cell cycle arrest.

\section{Materials and methods TCQA preparation}

For the in vitro assays, synthesized TCQA (97\% pure) was used. The stock solution was prepared in $70 \%$ ethanol and then TCQA was diluted in purified water and in the appropriate cell culture medium before adding to the cells. In this study, this compound was kindly provided by Dr. Kozo Sato from Synthetic Organic Chemistry Laboratories, the FUJIFILM Corporation (Kanagawa, Japan).

\section{Isolation of hAECs}

The amniotic samples from healthy human donors were collected during full-term C-sections. Then, an aseptic separation between the amnion and the chorion was assessed, and washing with $200 \mathrm{ml}$ Hank's Basic Salt Solution Calcium and Magnesium Free (CMF-HBSS) to eliminate blood clots was conducted. The membrane was cut into small parts using sterile surgical scissors and placed then in $50 \mathrm{ml}$ tubes where a pre-digestion buffer (CMF-HBSS, $0.5 \mathrm{mM}$ Ethylene Glycol-bis $\beta$-Aminoethyl Ether (EGTA), $20 \mathrm{ml}$ ) was added under a slight agitation for $30 \mathrm{~s}$. The previous solution was discarded and the different parts of the amnion were transferred to new 50 
tubes containing $20 \mathrm{ml}$ of the pre-digestion buffer following by $10 \mathrm{~min}$ incubation at $37^{\circ} \mathrm{C}$. After removing the pre-digestion buffer, a solution of $20 \mathrm{ml}$ of $0.05 \%$ trypsinEDTA was added to the tissue for $40 \mathrm{~min}$ at $37{ }^{\circ} \mathrm{C}$ and then the tubes were placed on ice. The culture medium Dulbecco's Modified Eagle Medium (DMEM) (Gibco, Karlsruhe, Germany) supplemented with 10\% Fetal Bovine Serum (FBS) (Gibco, Karlsruhe, Germany) and $0.1 \%$ Penicillin/Streptomycin (Gibco, Karlsruhe, Germany) was added to the trypsin digest and centrifuged at $200 \mathrm{~g}$ for $10 \mathrm{~min}$ at $4{ }^{\circ} \mathrm{C}$. The pellet was resuspended in $10 \mathrm{ml}$ of the medium and then filtered with a $100 \mu \mathrm{m}$ filter (BD Falcon, England, UK) to eliminate the tissue aggregates. The cell suspension containing the amnion epithelial cells was collected and the membrane was discarded.

\section{Cell culture}

HAECs were extracted then maintained in Placenta Epithelial Cell Basal Medium (PromoCell, Heidelberg, Germany). The medium was changed every other day and the cells were constantly monitored to detect if any change occurs in the morphology or structure. The cells were cultured in suspension and for subculture, the cells were washed twice with $10 \mathrm{ml}$ Phosphate Buffered Saline (PBS), then $3 \mathrm{ml}$ of pre-warmed pre-digestion buffer was added to the cells for $5 \mathrm{~min}$ at $37^{\circ} \mathrm{C}$. The cells were trypsinized for $10 \mathrm{~min}$ prior to adding $5 \mathrm{ml}$ of DMEM, then centrifuged at $200 \mathrm{rpm}$ for $4 \mathrm{~min}$ at $4{ }^{\circ} \mathrm{C}$. The supernatant was discarded and the pellet was resuspended in the culture medium and centrifuged again under the same conditions. The supernatant was removed and the cells were resuspended in the placental cell medium before seeding in Petri dishes.

\section{D spheroid culture}

The hAECs were cultured in 3D system. Firstly, a solution of $50 \mathrm{mg}$ Lipidure TM (NOF Corporation, Tokyo,

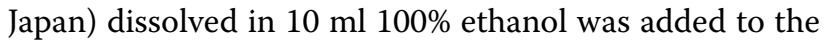
3D culture plate (Kuraray Co, Tokyo, Japan) for $2 \mathrm{~min}$. After removing the solution and a $3 \mathrm{~h}$ drying, $400 \mu \mathrm{l}$ PBS was placed in each well and the plate was centrifuged for $15 \mathrm{~min}$ at Room Temperature (RT), and checked under the microscope to ensure that there was no bubble formation. The PBS was then discarded and a washing with new PBS solution was conducted twice and the plates were then ready for 3D culture.

The cells were seeded at a density of $1 \times 10^{6}$ in Placenta Basal Epithelial Cell Medium into each well of the previously prepared culture plates to ensure the spheroids formation. Day 0 control (D0 control) samples were collected before adding the treatment to the cells. The cells were maintained for one-week culture with changing the medium with 0 and $20 \mu \mathrm{M}$ TCQA every $48 \mathrm{~h}$. At the end of the week, we established two groups: the treatment (D7 TCQA) and control (D7 control).

\section{RNA extraction}

The total RNA was extracted using ISOGEN kit (Nippon Gene, Tokyo, Japan) following the manufacturer's instructions. The hAECs were cultured as previously described, then washed with cold PBS before the total RNA extraction. The total RNA was quantified using a NanoDrop 2000 spectrophotometer (NanoDrop Technologies, Massachusetts, USA).

\section{Microarray analysis}

Microarray hybridization probes were generated from isolated RNA extracted from the hAECs treated with 0 or $20 \mu \mathrm{M}$ TCQA using ISOGEN solution (Nippon Gene, Tokyo, Japan) following the manufacturer's instructions. Briefly, the extracted RNA was amplified and biotinlabeled as aRNA. Then, the fragmented, biotin-labeled aRNA was hybridized to the Affymetrix Human Array strips (HG U219) containing probes for approximately 45,141 transcripts and variants. The chips were washed and stained in the Gene Atlas Fluidics Station 400 (Affymetrix, Santa Clara, USA) and the resulting image was scanned using the Gene Atlas Imaging Station (Affymetrix, Santa Clara, USA). The generated data were normalized using the Transcriptome Analysis Console (TAC) Software (version 4.0.1) following the Robust Multichip Average (RMA) algorithm. Gene expression values refer to Tukey's Bi-weight average of gene level intensity of all the replicates in a condition. Genes with a fold change $\geq 1.3$ (in linear space) and $P$-value $\leq 0.05$ (One-way between-subject ANOVA) were considered as differentially expressed genes (DEGs). Database for Annotation, Visualization, and Integrated Discovery (DAVID) bioinformatics resources 6.8 and Gene Set Enrichment Analysis (GSEA) were used for further Gene Ontology (GO) analysis of DEGs in each set of comparison [35-37]. GOs and pathways with p-value $<0.05$ (modified Fisher's Exact test with default EASE score threshold 0.1) were considered significant.

\section{Quantitative real-time PCR analysis}

The hAECs were cultured, treated, and the total RNA was extracted as described above. The RNA was extracted from the three groups: D0 control, D7 control, and D7 TCQA. The cDNA was synthesized from the extracted RNAs using SuperScript IV reverse transcription kit (Invitrogen, CA, USA) with a cycling protocol as follows: $95{ }^{\circ} \mathrm{C}$ for $10 \mathrm{~min}, 40$ cycles of $95^{\circ} \mathrm{C}$ for $15 \mathrm{~s}$, and $60{ }^{\circ} \mathrm{C}$ for $1 \mathrm{~min}$. The real-Time PCR was performed using 7500 Fast Real-Time PCR Software 1.3.1 (Applied 
Biosystems, CA, USA) with TaqMan probes specific to CTNNB1, BMP5, Melanocortin 1 Receptor (MC1R), Dermokine ( $D M K N)$, Cyclin-Dependent Kinase Inhibitor 1 (p21), Versican (VCAN), Interleukin 6 (IL6), and Tumor Necrosis Factor Alpha (TNFa) (Applied Biosystems, CA, USA). GAPDH (Applied Biosystems, CA, USA) was used as an endogenous control. In order to calculate the relative mRNA expression levels using the endogenous control, the $2-\Delta \Delta \mathrm{Ct}$ method was assessed.

\section{Statistical analysis}

For the quantitative real-time PCR, all the experiments were performed three times and the results were expressed as mean of \pm standard deviation (SD). The Student's t-test was performed when two groups were compared. $P$-value of $\leq 0.05$ was considered significant.

\section{Ethics approval}

The protocol of extraction of hAECs was checked and approved by the Ethical Review Committee of the University of Tsukuba. Informed written consent was obtained from the mothers who donated the placenta after delivery.

\section{Results}

TCQA affected differentiation-associated genes in seven days treated hAECs compared with Day 0 control

The RNA was collected from hAECs at Day 0 prior to treatment and seven days after treatment with $20 \mu \mathrm{M}$ TCQA, then global gene expression analysis was conducted on two biological replicates (D7 TCQA-treated and D0 control hAECs). Results revealed that 3119 genes were differentially modulated by TCQA, out of which, 707 were upregulated while 2421 downregulated (Fig. 1a).

Figure $1 \mathrm{~b}$ illustrated the GOs of the upregulated gene after seven days of treatment compared with D0 control. TCQA significantly enhanced genes associated with metabolic process (GO: 0,016,071), neuron differentiation (GO: 0,030,182), epithelial cell differentiation (GO: $0,030,855$ ), regulation of cell differentiation (GO: $0,045,595$ ), and nervous system process (GO: 0,050,877). Analysis of the upregulated pathways revealed that the affected signaling are Wnt/ $\beta$-catenin, Fibroblast Growth Factor (FGF), Notch, Sonic Hedgehog (Shh), and neural differentiation-related pathways (Fig. 1c).

On the other hand, TCQA negatively modulated genes significant for the regulation of the cell cycle (GO:
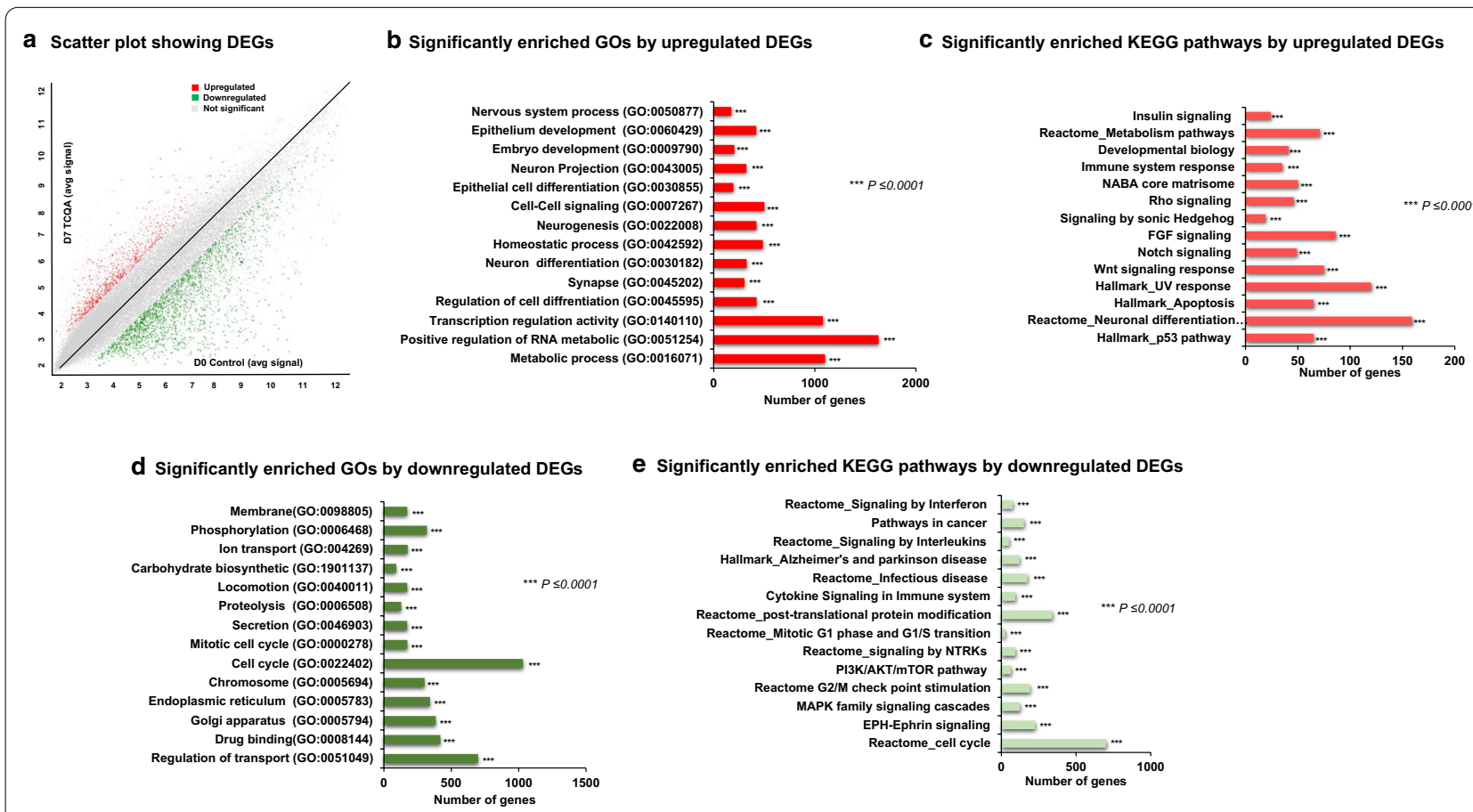

Fig. 1 Microarray profiling of D7 TCQA-treated versus D0 control hAECs. a Scatter plot showing the DEGs. X-axis represents the average signal intensities (log2) in D0 control. Y-axis represents the average signal intensities (log2) in D7 TCQA-treated hAECs. The red color represents the upregulated DEGs, green color represents the downregulated DEGs, and grey color represents the nonsignificant genes. b Significantly enriched GOs by upregulated (analyzed using GSEA). c Significantly enriched KEGG pathways by upregulated DEGs (analyzed using DAVID and GSEA). d Significantly enriched GOs by downregulated (analyzed using GSEA). e Top significantly enriched KEGG pathways by the downregulated DEGs (analyzed using DAVID and GSEA). Each bar is arranged according to significance (p-values) and represents the number of DEGs 
0,022,402), mitotic cell division (GO: 0,000,278), and drug binding (GO: 0,008,144) (Fig. 1d). For the downregulated pathways, we observed the regulation of Mitogen-Activated Protein Kinases (MAPK) pathway, PI3K/ $\mathrm{AKT} / \mathrm{mTOR}$, cytokine and interferon signaling, neurodegenerative diseases, and cell cycle progression and transition-related pathways (Fig. 1e). These results indicated that seven days of treatment with TCQA compared with D0 control, positively regulated neurogenesis and induced epithelial and neuronal cell differentiation, while repressing genes linked with inflammation and cell cycle progress and division, which favorite differentiation over proliferation in hAECs.

Interestingly, we compared D7 TCQA versus D7 control with D7 control versus D0 control to observe the fate of hAECs without treatment. A Venn diagram was created to compare the DEGs between the two sets of comparisons (Fig. 2a). Clustering analysis was then performed and the upregulated genes by D7 TCQA versus D7 control comparing with D7 control versus D0 control were linked to cell differentiation, neurogenesis, cell cycle arrest, and pigment cell differentiation. The comparison of the downregulated genes showed the modulation of genes related to cell activation, cell cycle, and regulation of cell proliferation (Fig. 2b).

Moreover, a comparison between D7 TCQA versus D0 control with D7 TCQA versus D7 control was performed and the results showed as well an upregulation in differentiation-related pathway upon TCQA treatment (Additional file 1: Suppl Fig. 1).

\section{TCQA enhanced neuronal and pigment cell} differentiation-associated genes in seven days treated hAECs compared with Day 7 control

DNA-microarray analysis was assessed on two biological replicates (D7 TCQA-treated and D7 control hAECs). GSEA showed that several priori-defined gene sets associated with cell differentiation (GO: 0,045,595) including pigment cell (GO: 0,050,931) and neuron cells (GO: 0,030,182), epidermis development (GO: 0,008,544),

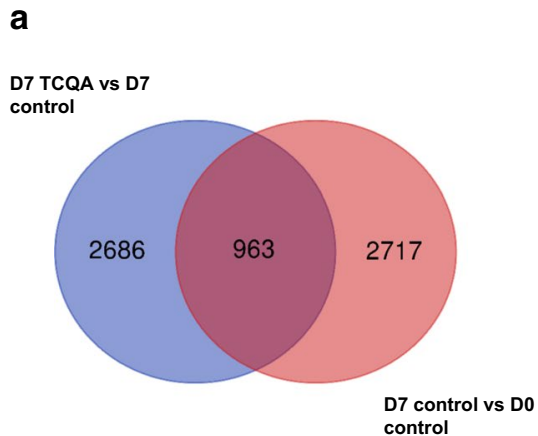

b

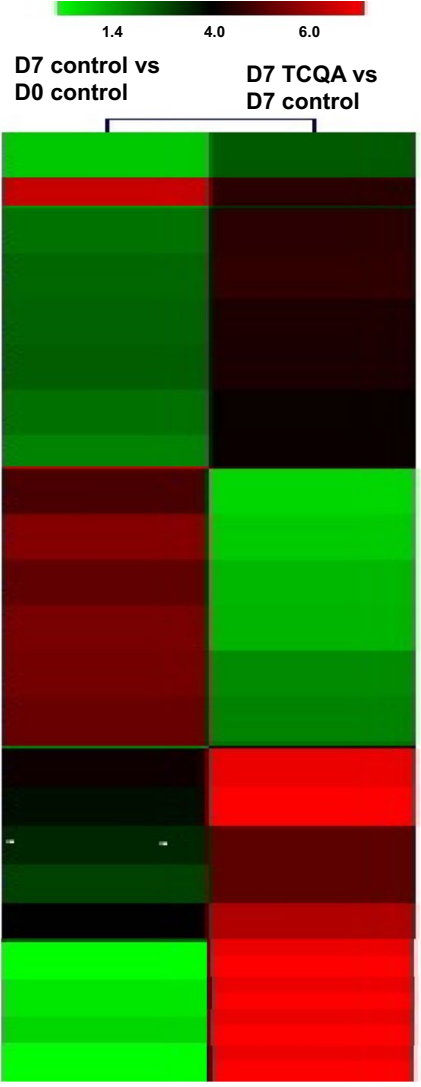

Cell activation (GO: 0001775)

Protein phosphorylation (GO: 0006468)

Neurogenesis (GO: 0022008)

Neuron differentiation (GO: 0030182)

Synapse (GO: 0045202)

Homeostatic process (GO: 0042592)

Collagen binding (GO: 0005518)

Nervous system (GO: 0050877)

Locomotion (GO: 0040011)

Golgi apparatus (GO: 0005794)

Regulation of cell proliferation (GO: 0042127)

Protein transport (GO: 0015031)

Embryo development (GO: 0009790)

Response to cytokines (GO: 0034097)

Metabolic process (GO: 0016071)

Positive regulation of RNA metabolic (GO: 0051254)

Regulation of cell death (GO: 0010941)

ATP binding (GO: 0005524)

Regulation of stress response (GO: 0080134)

Response to lipid (GO: 0033993)

Pigment cell differentiation (GO: 0050931)

Oxidation reduction process (GO: 0055114)

Chromosome (GO: 0005694)

Fig. 2 Comparison of gene profiling between D7 TCQA-treated versus D7 control hAECs with D7 control versus D0 control. a Venn diagram showing common and unique sets of DEGs between each exposure. $\mathbf{b}$ Heat map showing the significance of biological processes in two comparison sets - D7 control versus D0 control and D7 TCQA-treated versus D7 control hAECs. Heat map was generated using Morpheus online software (https://software.broadinstitute.org/morpheus) 
negative regulation of cell cycle transition (GO: $1,901,987$ ), DNA repair (GO: $0,006,281$ ), and oxidationreduction process (GO: 0,055,114) were significantly enriched by the DEGs between D7 TCQA and D7 control cells (Fig. 3a). Then to know more about the upregulated pathway, DAVID analysis was performed and results showed an upregulation of differentiation-related pathways such as Wnt/ $\beta$-catenin, BMP, Notch, ErbB, and Tumor Protein p53 (p53) (Fig. 3b). Additionally, TCQA affected Foxo pathway, insulin signaling, and Tricarboxylic Acid (TCA) cycle (Fig. 3b). The DEG were classified according to their function and $22 \%$ of the genes are classified as cell differentiation markers, $8 \%$ as tumors suppressors, and $48 \%$ as transcription factors (Fig. 3c).

The top 12 upregulated genes in D7 TCQA-treated hAECs were classified in Table 1 . The most affected genes were associated with cell cycle arrest including $p 21$ with a fold-change of 4.71. Additionally, genes involved with pigment and neural cell differentiation like CTNNB1, $V C A N, B M P 5, D M K N$, and $M C 1 R$, were upregulated up to 2.66, 2.27, 2.12, and 2.02 fold-change, respectively (Table 1). Putting these results together, TCQA stimulated the differentiation of hAECs towards neural and pigment cell lineage.
TCQA downregulated cell cycle and inflammation-associated genes in seven days treated hAECs compared with day 7 control

Previously, we showed that TCQA downregulated cell cycle and inflammation-related genes compared with Day 0 control. This effect is confirmed as well comparing TCQA and Day 7 control as illustrated in Fig. 3d. Moreover, GO analysis showed a downregulation in the regulation of cell proliferation (GO: 0,042,127), cell activation (GO: 0,001,775), and negative regulation of cell differentiation (GO: 0,045,596) (Fig. 3d). KEGG pathway analysis showed the downregulation of G2/M checkpoint, interleukins, TNF $\alpha / N F-k B$ signaling, and Inteferon Gamma (IFNY) signaling (Fig. 3e). The classification of the genes according to their function revealed that TCQA negatively modulated 15\% cytokines and growth factors, $4 \%$ cell differentiation markers, 3\% tumors suppressors, and 60\% transcription factors (Fig. 3f). Table 2 summarizes the top downregulated genes by TCQA upon seven days of treatment in hAECs. Inflammatory genes expression such as $T N F \alpha$, IL6, and Interleukin 8 (IL8) was downregulated by TCQA up to a fold-change, respectively, $-3.65,-3.32$, and -2.88 (Table 2).

Hence, TCQA stimulated the differentiation of hAECs via decreasing the cell cycle activity and the cell proliferation rate. Moreover, it has an anti-inflammatory activity as it decreased cytokines and interleukins-related genes.

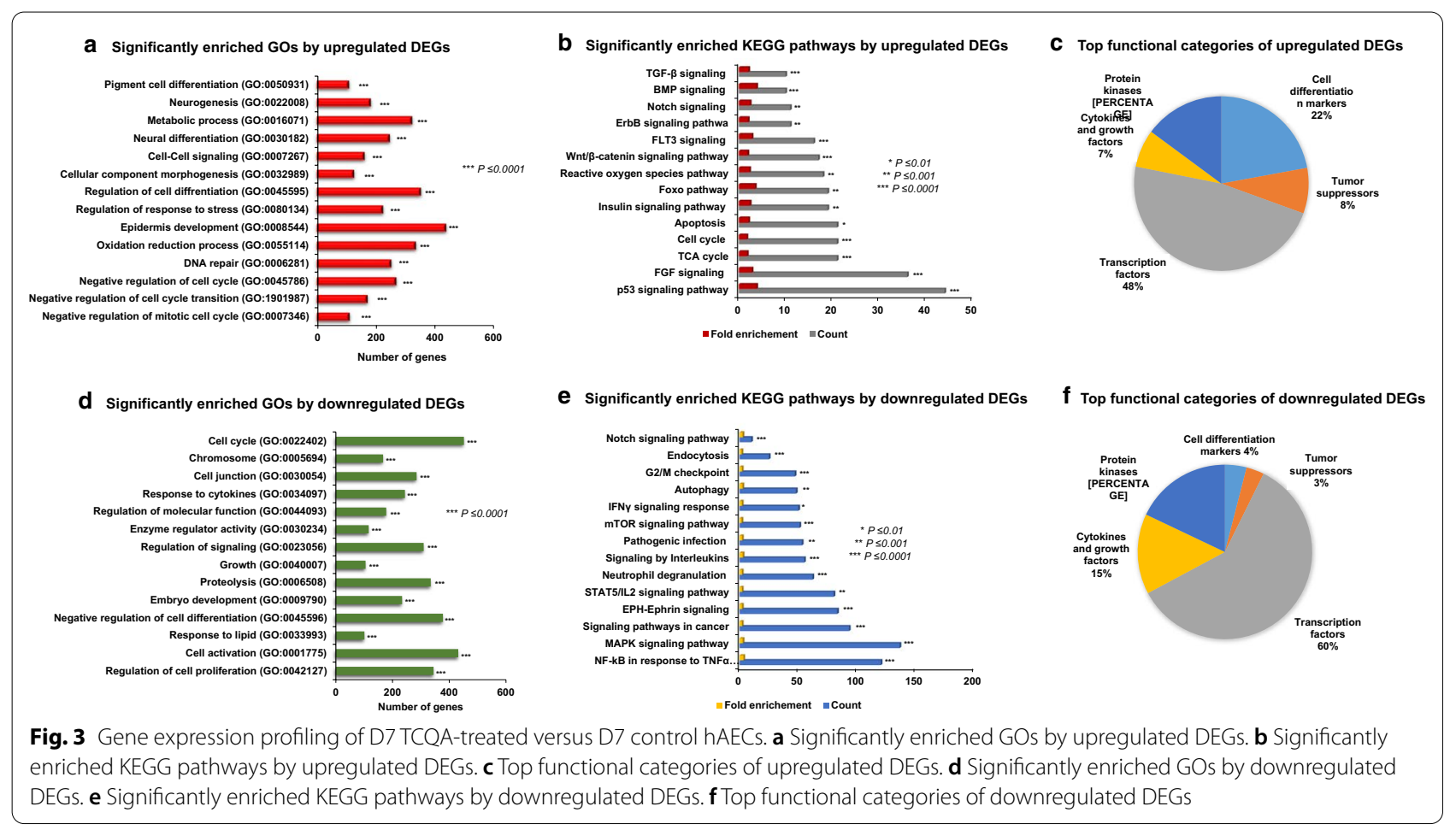


Table 1 Top upregulated genes in D7 TCQA-treated hAECs (vs D7 control) *

\begin{tabular}{|c|c|c|c|c|}
\hline Gene symbol & Gene name & Biological function & Fold-change & $P$ value ${ }^{* *}$ \\
\hline p21 & Cyclin-dependent kinase inhibitor 1 & Tumor suppressor; Cell cycle arrest & 4.71 & 0.005 \\
\hline DYNC1H1 & $\begin{array}{l}\text { dynein cytoplasmic } 1 \text { heavy chain } 1 \\
\text { inhibitor } 2\end{array}$ & Tumor suppressor; Cell cycle arrest & 2.74 & 0.028 \\
\hline CTNNB1 & Catenin (cadherin associated protein), beta 1 & $\begin{array}{l}\text { Melanocytes stem cells differentiation; Neural dif- } \\
\text { ferentiation; pigmentation }\end{array}$ & 2.66 & 0.040 \\
\hline TCF4 & Transcription factor 4 & Canonical Wnt signaling pathway activation & 2.48 & 0.005 \\
\hline VCAN & Versican & Intercellular signaling; Regulation of differentiation & 2.27 & 0.031 \\
\hline CDKN1 & Cyclin-dependent kinase inhibitor 1 & Tumor suppressor; Cell cycle arrest & 2.22 & 0.004 \\
\hline BMP5 & Bone morphogenetic protein 5 & $\begin{array}{l}\text { Neural crest cell survival; dendritic growth; Keratino- } \\
\text { cyte and skin stem regulation }\end{array}$ & 2.12 & 0.002 \\
\hline$D M K N$ & Dermokine & Regulator of keratinocyte differentiation & 2.07 & 0.002 \\
\hline MC1R & Melanocortin 1 receptor & $\begin{array}{l}\text { Melanin biosynthetic process; pigmentation; pig- } \\
\text { ment cell regulation }\end{array}$ & 2.02 & 0.047 \\
\hline GATA2 & GATA binding protein 2 & $\begin{array}{l}\text { Nervous system development; Neuron and den- } \\
\text { dritic cell differentiation; Wound healing }\end{array}$ & 1.91 & 0.025 \\
\hline NDUFS2 & NADH:ubiquinone oxidoreductase core subunit S2 & Oxidation-reduction process, ATP synthesis & 1.85 & 0.021 \\
\hline FOXRED1 & $\begin{array}{l}\text { FAD-dependent oxidoreductase domain contain- } \\
\text { ing } 1\end{array}$ & Oxidation-reduction process, ATP synthesis & 1.77 & 0.001 \\
\hline
\end{tabular}

*Genes functions were obtained from NCBI. ${ }^{* *}$ ANOVA was performed to assess the level of significance between groups

Table 2 Top downregulated genes in D7 TCQA-treated hAECs (vs D7 control) *

\begin{tabular}{|c|c|c|c|c|}
\hline Gene symbol & Gene name & Biological function & Fold-change & $P$ value** \\
\hline$T N F a$ & Tumor necrosis factor alpha & $\begin{array}{l}\text { Inflammatory response; Cell activation; Cell death; } \\
\text { Negative regulation of apoptotic process }\end{array}$ & -3.65 & 0.004 \\
\hline $1 L 6$ & Interleukin 6 & $\begin{array}{l}\text { Negative regulation of collagen biosynthesis; Inflam- } \\
\text { matory response; Cytokine response }\end{array}$ & -3.32 & 0.009 \\
\hline 128 & Interleukin 8 & $\begin{array}{l}\text { Pro-inflammatory response; Angiogenesis; Phagocy- } \\
\text { tose }\end{array}$ & -2.88 & 0.016 \\
\hline FOS & FBJ osteosarcoma oncogene & Cyclin D1 activation; Cell cycle regulation & -2.80 & 0.001 \\
\hline$A B C G 1$ & ATP-binding cassette transporter G1 & Cholesterol accumulation; $T$ cell homeostasis alteration & -2.65 & 0.045 \\
\hline PTGS2 & Prostaglandin G/H synthase 2 & $\begin{array}{l}\text { Production of inflammatory prostaglandins; Cell adhe- } \\
\text { sion; Resistance to apoptosis; Tumor angiogenesis }\end{array}$ & -2.65 & 0.033 \\
\hline SORT1 & Sortilin & $\begin{array}{l}\text { Neuronal apoptosis: Coronary artery disease; Tumor } \\
\text { cell survival }\end{array}$ & -2.45 & 0.012 \\
\hline GPNMB & Glycoprotein non-metastatic melanoma protein B & $\begin{array}{l}\text { Alzheimer disease marker; Regulator of melanoma } \\
\text { tumor growth }\end{array}$ & -2.43 & 0.004 \\
\hline IRF2 & Interferon regulatory factor 2 & Oncogene; Human leukaemia cell growth & -2.24 & 0.001 \\
\hline$K L K 6$ & Kallikrein-6 & $\begin{array}{l}\text { Pathogenesis of Parkinson disease; Collagen and fila- } \\
\text { ment degradation }\end{array}$ & -2.22 & 0.023 \\
\hline TRPV3 & $\begin{array}{l}\text { Transient receptor potential cation channel sub- } \\
\text { family } \vee \text { member } 3\end{array}$ & $\begin{array}{l}\text { Negative regulator of hair growth and cycling; Sup- } \\
\text { presses keratinocyte proliferation }\end{array}$ & -2.17 & 0.043 \\
\hline IFNLR1 & Interferon, lambda receptor 1 & Inflammatory and cytokine response & -2.12 & 0.002 \\
\hline
\end{tabular}

${ }^{*}$ Genes functions were obtained from NCBI. ${ }^{* *}$ ANOVA was performed to assess the level of significance between groups

TCQA regulated cell differentiation, inflammation, cell cycle, and ATP content in seven days treated hAECs To understand more the effect of TCQA on hAECs, a heat map was created using Morpheus software. Results revealed that TCQA had five main functions: stimulation of neural and pigment cell differentiation, cell cycle arrest, tumor suppressor and apoptosis regulator, ATP content stimulator, and anti-inflammatory activity (Fig. 4a). In addition, the microarray results were further confirmed by RT-PCR that showed an enhancement of the gene expression of CTNNB1, BMP5, VCAN, MC1R, and $D M K N$ known to be involved in neural and pigment 


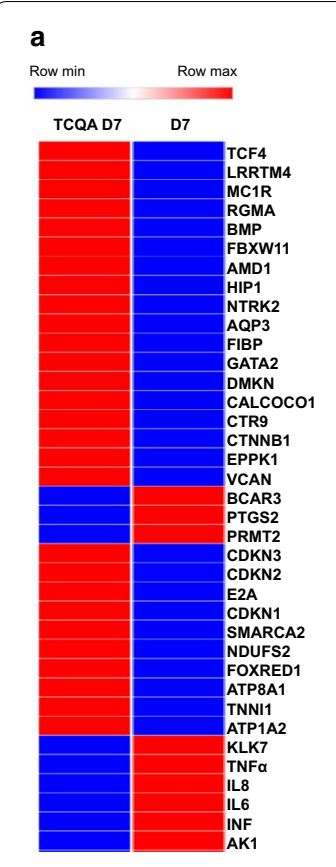

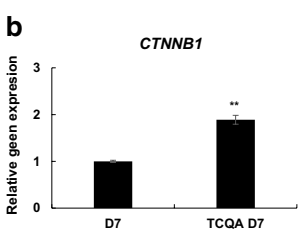

BMP5

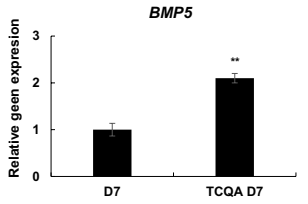

CDKN3

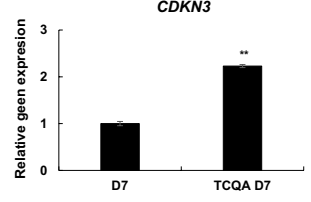

IL6

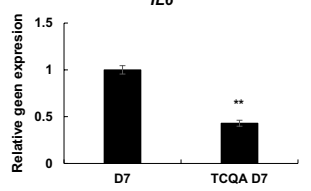

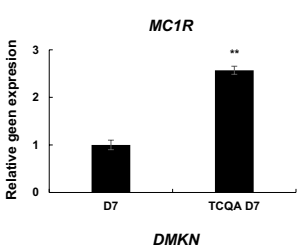

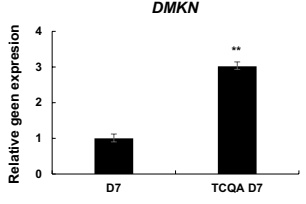

VCAN

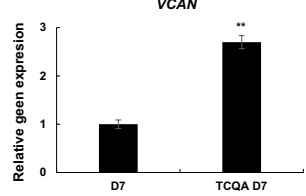

TNFo

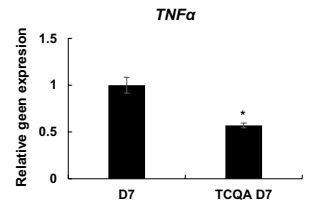

C

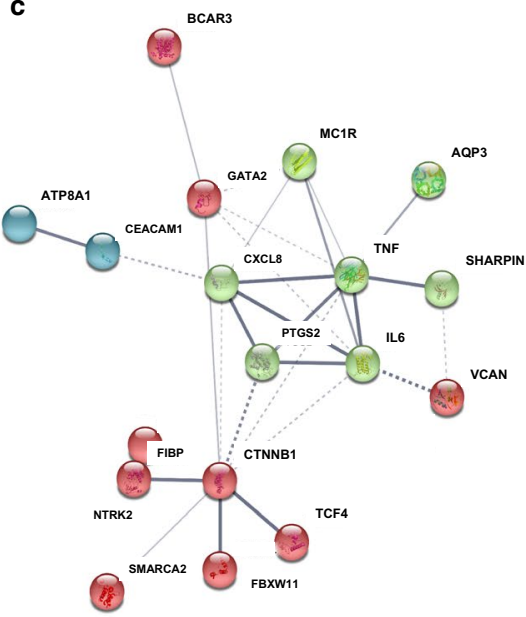

Fig. 4 Molecular functions induced in D7 TCQA-treated compared with D7 control hAECs. a Heat map showing relative expression intensities of DEGs. Heat map was generated using Morpheus software. b Gene expression of CTNNB1, MC1R, VCAN, DMKN, IL6, and TNFa in D7 TCQA-treated and D7 control hAECs. The mRNA level was quantified using TaqMan real-time PCR. Results represent the mean \pm SD of three independent experiments. The Student's t-test was used to compare the mean values of two groups. ${ }^{*} P \leq 0.05 ;{ }^{*} P \leq 0.01$. c Possible protein interactions among the genes classified in the heat map. Figure was generated using an online software STRING (https://string-db.org/)

cell differentiation process. Whereas, p21 gene expression was investigated because of its role in cell cycle arrest (Fig. 4b). On the other hand, the expression of IL6 and TNF $\alpha$ was negatively regulated after seven days of treatment, further proving the anti-inflammatory effect of TCQA (Fig. 4b). To look for possible protein interaction between the genes previously grouped in the heat map, STRING software was used. Figure $4 \mathrm{c}$ represents the obtained results showing that there is an interaction between the DEG on the protein level.

\section{Discussion}

Recently, scientists are looking for new sources of cells for regenerative medicine. Human amniotic membrane consists of an epithelial layer, a basal lamina, and an avascular mesenchymal layer [38]. The epithelial layer contains a high number of epithelial cells, which are gaining a great interest in cell-based therapies and considered to have the potential to overcome the existing challenges such as immunological rejection, tumorigenesis, and ethical problems [5, 39].

HAECs are multipotent cells because of their ability to differentiate into different lineages [40]. Plant extracts and their bioactive compounds have received considerable attention and been accepted in the mainstream of medicine, especially because of their protective properties and their potential to induce the proliferation and differentiation of stem cells [41]. In this current study, we showed the effect of the polyphenolic compound TCQA on inducing the differentiation of hAECs into neural and pigment cell lineage via the upregulation of differentiation- and cell cycle arrest-associated genes. Additionally, TCQA has been found to exhibit an anti-inflammatory and ATP stimulating effect.

In this study, the hAECs were obtained from Tsukuba Human Tissue Biobank Center (THB) established at Tsukuba University Hospital [42]. Primarily, from each placenta sample (donated by healthy mothers who underwent cesarean section), three sets of specimens were collected for the collection of placenta-derived somatic stem cells: umbilical cord for endothelial progenitor cells, Wharton's jelly for mesenchymal stem cells, and amniotic membrane for amniotic epithelial stem cells. The primary amniotic epithelial cells were heterogeneous; however, the hAECs isolated from the adherent subpopulations of passaged primary cells could widely express stemness 
markers [43]. Besides, hAECs cultured in a 3D microenvironment as spheroids have highly expressed the stemness-related genes compared to their 2D counterpart as well as compared to iPSCs and MSCs [18].

Firstly, we compared D7 TCQA-treated hAECs with D0 untreated control hAECs. Our findings showed that TCQA significantly enriched neurogenesis-, nervous system process-, neuron and epithelial cell differentiation-associated genes (Fig. 1). Actually, several studies reported that hAECs express neural markers even before differentiation and they can synthesize and release dopamine, acetylcholine, noggin, catecholamines, and neurotrophic factors; and as mentioned previously, hAECs have a potential to differentiate into neural lineage upon rosmarinic acid treatment [13, 18, 44]. Various signaling pathways are engaged in the process of neural development and hNSC differentiation. Wnt signaling has been implicated in promoting self-renewal during neural development and it has been shown that this pathway is considered to be a cell-cell and a cell-matrix contactregulated inducer of neurogenesis [45, 46]. FGF pathway has a key role in early neural differentiation and development, the acquisition of neural identity, and chromatin regulation [47-49]. Hence, signaling pathways control neuron fate and regulation, and this activity is achieved through their regulatory interactions to decrease or enhance an activity. The Wnt/ $\beta$-catenin and FGF pathways regulate not only neuronal stem cell differentiation but also proliferation, and it is known that the crosstalk and the balance between them induce the growth and the development of adult brain, and the appropriate segregation of neuronal populations [50, 51]. Here, upon TCQA treatment, Wnt- and FGF-related genes were upregulated in seven days treated hAECs compared with D0 control. Interestingly, hAECs not only showed differentiation markers but also neurogenesis genes were significantly stimulated (Fig. 1b, c). This result can be explained by the upregulation of Notch pathway known to regulate neurogenesis and brain development positively at both embryonic and adult stages [52].

Results showed as well a downregulation in cell cycle and inflammation significant genes and pathways (Fig. 1d, e). In addition, we checked the effect of D7 TCQA with D7 control and we compared them with D7 control versus D0 control. TCQA treatment significantly regulated genes linked with cell cycle arrest, regulation of cell differentiation, and neurogenesis (Fig. 2). On the other hand, it downregulated genes and pathways involved with cell activation, cytokine response, and embryonic development (Fig. 2). Therefore, TCQA stimulated the differentiation of hAECs compared with the untreated cells. GSEA analysis of D7 TCQA versus D7 control, showed that TCQA enriched pigment cell differentiation, epidermis development, and oxidation-reduction sets and upregulated Wnt/ $\beta$-catenin and ErbB signaling pathways (Fig. 3a, b). The Wnt/ $\beta$-catenin signaling pathway plays an important role in the regulation of pigmentation, melanocyte development, and melanocyte stem cell differentiation [53, 54]. Previously, we reported the effect of TCQA on increasing the pigmentation in human melanocytes, in B16F10 cells, and in eight-weeks-old C3H male mice through the upregulation of $\beta$-catenin and its target genes and, to enhance the protein expression of CD34 known as a melanocytes stem cells differentiation marker [32]. The EdnrB pathway is implicated in melanocytes stem cell regeneration and differentiation via crosstalk with Wnt signaling [55].

The GO analysis revealed that TCQA positively stimulated neural cell differentiation, cell cycle arrest, and neurogenesis, compared with D7 control (Fig. 3). Actualy, no obvious morphological changes supporting neurological or pigment cell differentiation could be observed due to the spheroid structure of the cells. Moreover, the treatment duration was only seven days, which may be enough to induce early biological events for directed differentiation but is too early to observe any obvious cell morphology changes. Cell cycle regulation is involved in a large array of intracellular differentiation events and several researches established that G0/G1 cell cycle arrest is related to differentiation [56]. The p53 pathway is known to be an important regulatory factor of G0/G1 arrest, and it was regulated by TCQA in treated-hAECs (Fig. 3b). As reported previously, TCQA induces cell cycle arrest and differentiation of hNSCs into three kinds of cells; neuron, oligodendrocyte, and astrocyte [29]. Interestingly, melanocyte precursors are originally derived from the neural crest cells; thus, our current study suggests that TCQA increased G0/G1 arrest by negatively regulating G1/S transition via changing expressions of various genes and moving hAECs toward more lineage-committed cells like neural and pigment cells.

It is important to note that cell cycle can regulate neurogenesis as this process involves proliferation and differentiation [57]. TCQA upregulated the GO of neurogenesis and Notch pathway-related genes (Fig. 3a, b). Notch signaling is essential during embryonic developmental periods of brain, and to maintain the balance between quiescence and active neurogenesis of neural stem cells [58]. The current data showed as well a stimulation of BMP, Transforming Growth Factor Beta (TGF- $\beta$ ), and FGF signaling pathways (Fig. 3). It is widely known that BMP signaling pathway is involved in neural fate commitment, stem cell differentiation, and neurogenesis promotion [59]. On the other hand, the role of TGF- $\beta$ 
family in multiple aspects of the nervous system development and function is well established. During adulthood, TGF- $\beta$ signaling modulates inflammatory responses and plays a protective role against neurodegenerative diseases [60]. These results correlated with the downregulation of inflammation-related genes in TCQA-treated hAECs compared with D7 control (Fig. 3d, e). Next, the highly affected genes by TCQA, whether up or downregulated, are clustered in a heat map showing the differentiation regulation, anti-inflammatory, ATP stimulation, and cell cycle arrest activities of this compound; then some of these genes were validated including $C T N N B 1, M C 1 R$, BMP5, DMKN, p21,VCAN, IL6, and TNF (Fig. 4a, b, and Tables 1 and 2). The role of $\beta$-catenin in the regulation of pigment and neural stem cells differentiation is previously explained in this study, as for MC1R is established as the main factor dictating pigmentation and melanocytes differentiation $[61,62]$. DMKN was identified as one of the most highly expressed genes in keratinocytes, another type of pigment cell, and is involved in their differentiation [63]. VCAN is expressed in human fibroblast and the Extracellular Matrix (ECM) and reported to induce neuronal differentiation and promote neurite outgrowth [64]. For the cell cycle arrest activity, the gene expression of p21 was checked, as we found that p53 pathway was stimulated by TCQA (Figs. 3 and 4, and Table 1). Phosphorylated p53 activates p21, leading to the inhibition of G1/S transition and promoting cell cycle arrest [65]. BMP5 regulates neural crest cell survival, proliferation, and differentiation and promotes dendritic growth $[66,67]$. For the inflammatory genes, IL6 expression was checked because it is an important activator of inflammation and directs the transition from innate to acquired immunity, and is related to pathological situations [68]. Another pro-inflammatory cytokine is TNF $\alpha$ known to interact with IL6 and is associated with neuro-inflammatory response that is linked with several neurological disorders [69]. To look for possible protein interaction between the previously clustered genes, software STRING was used and revealed a potential protein interaction between these genes (Fig. 4c).

Putting together, this study showed that TCQA induced the differentiation of hAECs toward pigment and neural cell lineage by upregulating Wnt, BMP, FGF, and TGF- $\beta$ signaling pathways. The downregulation of cell cycle-related genes and the upregulation of cell cycle arrest genes contributed to further enhance the differentiation potential of TCQA. Furthermore, TCQA was found to have antioxidant, anti-inflammatory, and ATP stimulating activities. However, further in-depth investigations on the effects of TCQA treatment on morphology, physiology, and protein expression pattern of hAECs are needed to confirm its differentiation effect.

\section{Supplementary information}

The online version contains supplementary material available at https://doi. org/10.1186/s12964-020-00697-5.

Additional file 1: Fig. S1. Comparison gene profiling between D7 TCQAtreated vs D0 control hAECs and D7 TCQA-treated vs D7 control hAECs. A) Venn diagram showing common and unique upregulated sets of DEGs between each exposure. Blue circles denote DEGs between D7 TCQAtreated vs D0 control hAECs and red circles denote DEGs between D7 TCQA-treated vs D7 control hAECs. B) GO analysis of the common upregulated genes set between the two comparison sets. C) Venn diagram showing common and unique downregulated sets of DEGs between D7 TCQA-treated vs D0 control hAECs and D7 TCQA-treated vs D7 control hAECs. D) GO analysis of the common downregulated genes set between the two comparison sets.

\section{Abbreviations}

HAECs: Human Amnion Epithelial Cells; TCQA: 3,4,5-Tri-O-Caffeoylquinic Acid; ESCs: Embryonic Stem Cells; MSCs: Mesenchymal Stem Cells; HAMSCs: Human Amnion Mesenchymal Stromal Cells; CQA: Caffeoylquinic Acid; ATP: Adenosine Triphosphate; SAMP8: Senescence-Accelerated Prone Eight; HNSC: Human Neural Stem cells; BMP: Bone Morphogenetic Protein; CMF-HBSS: Hank's Basic Salt Solution Calcium and Magnesium Free; EGTA: Ethylene Glycol-bis $\beta$-Aminoethyl Ether; DMEM: Dulbecco's Modified Eagle Medium; FBS: Fetal Bovine Serum ; PBS: Phosphate Buffered Saline; RT: Room Temperature; RMA: Robust Multichip Average; TAC: Transcriptome Analysis Console; DAVID: Database of Annotation, Visualization, and Integrated Discovery; GSEA: Gene Set Enrichment Analysis; MC1R: MelanoCortin 1 Receptor; DMKN: Dermokine; p21: Cyclin-Dependent Kinase Inhibitor; VCAN: Versican; IL6: Interleukin 6; TNFa: Tumor Necrosis Factors Alpha; SD: Standard Deviation; DEGs: Differentially expressed genes; GO: Gene Ontology; FGF: Fibroblast Growth Factor; Shh: Sonic Hedgehog; MAPK: Mitogen-Activated Protein Kinase; P53: Tumor Protein p53; TCA: Tricarboxylic Acid Cycle; IFNy: Interferon Gamma; IL8: Interleukin 8; TGF- $\beta$ : Transforming Growth Factor Beta; ECM: Extracellular Matrix.

\section{Acknowledgements}

We would like to thank Dr. Kozo Sato for providing synthesized TCQA. We are also grateful for the help extended by Dr. Kazunori Sasaki for RNA extraction.

\section{Authors' contributions}

MB performed Quantitative Real-Time PCR experiments, performed data analysis and interpretation, prepared the figures, and wrote the manuscript. FF performed microarray experiment and data curation and validation, edited and revised the manuscript. YZ was involved in the conception and methodology of the study, provided resource materials. OT contributed to the conception of the study and provided resource materials. HI conceived and supervised the study, managed funding and resources for the study and reviewed the manuscript. All authors read and approved the final manuscript.

\section{Funding}

This study was supported by Japan Science and Technology Agency (JST); Science and Technology Research Partnership for Sustainable Development (SATREPS, Grant No. JPMJSA1506).

\section{Data availability}

The data that support the findings of this study are available within the paper. The microarray data have been deposited to NCBI, GEO database (accession: GSE153617)

\section{Ethics approval and consent to participate}

The protocol of extraction of hAECs was checked and approved by the Ethical Review Committee of the University of Tsukuba. Informed written consent was obtained from the mothers who donated the placenta after delivery.

Consent for publication

Full consent for the publication of the performed experiments was obtained. 


\section{Competing interests}

The authors declare that they have no financial or commercial conflicts of interest.

\section{Author details}

${ }^{1}$ Alliance for Research On the Mediterranean and North Africa (ARENA), University of Tsukuba, Tsukuba, Japan. ${ }^{2}$ AIST-University of Tsukuba Open Innovation Laboratory for Food and Medicinal Resource Engineering (FoodMed-OIL), AIST, University of Tsukuba, Tsukuba, Japan. ${ }^{3}$ Faculty of Life and Environmental Sciences, University of Tsukuba, 1-1-1 Tennodai, Tsukuba, Ibaraki 305-8572, Japan. ${ }^{4}$ Department of Gastrointestinal and Hepato-Biliary-Pancreatic Surgery, Faculty of Medicine, University of Tsukuba, Tsukuba, Japan.

Received: 16 October 2020 Accepted: 10 December 2020 Published online: 24 February 2021

\section{References}

1. Maymó JL, Riedel R, Pérez-Pérez A, Magatti M, Maskin B, Dueñas JL, et al. Proliferation and survival of human amniotic epithelial cells during their hepatic differentiation. PLOS ONE. 2018;13:1-28.

2. Visweswaran M, Pohl S, Arfuso F, Newsholme P, Dilley R, Pervaiz S, et al. Multi-lineage differentiation of mesenchymal stem cells - to Wnt, or not Wnt. Int J Biochem Cell Biol. 2015;68:139-47. https://doi.org/10.1016/j. biocel.2015.09.008.

3. McDonald C, Siatskas C, Bernard CA. The emergence of amnion epithelial stem cells for the treatment of Multiple Sclerosis. Inflamm Regen. 2011;31:256-71.

4. Li JY, Christophersen NS, Hall V, Soulet D, Brundin P. Critical issues of clinical human embryonic stem cell therapy for brain repair. Trends Neurosci. 2008;31:146-53.

5. Miki T. Amnion-derived stem cells: in quest of clinical applications. Stem Cell Res Ther. 2011;2:25.

6. Yang PJ, Yuan WX, Liu J, Li J, Tan B, Qiu C, et al. Biological characterization of human amniotic epithelial cells in a serum-free system and their safety evaluation. Acta Pharmacol Sin. 2018;39:1305-16.

7. Miki T, Strom SC. Amnion-derived pluripotent/multipotent stem cells. Stem Cell Rev. 2006;2:133-41. https://doi.org/10.1007/s1201 5-006-0020-0.

8. Miki T, Lehmann T, Cai H, Stolz DB, Strom SC. Stem cell characteristics of amniotic epithelial cells. Stem Cells. 2005;23:1549-59.

9. Sakuragawa N, Kakinuma K, Kikuchi A, Okano H, Uchida S, Kamo I, et al. Human amnion mesenchyme cells express phenotypes of neuroglial progenitor cells. J Neurosci Res. 2004;78:208-14.

10. Cargnoni A, Di Marcello M, Campagnol M, Nassuato C, Albertini A, Parolini O. Amniotic membrane patching promotes ischemic rat heart repair. Cell Transplant. 2009;18:1147-59.

11. Ilancheran S, Michalska A, Peh G, Wallace EM, Pera M, Manuelpillai U. Stem cells derived from human fetal membranes display multilineage differentiation potential. Biol Reprod. 2007;77:577-88. https://doi. org/10.1095/biolreprod.106.055244

12. Mamede AC, Carvalho MJ, Abrantes AM, Laranjo M, Maia CJ, Botelho MF. Amniotic membrane: from structure and functions to clinical applications. Cell Tissue Res. 2012;349:447-58. https://doi.org/10.1007/s0044 1-012-1424-6.

13. Insausti CL, Blanquer M, García-Hernández AM, Castellanos G, Moraleda JM. Amniotic membrane-derived stem cells: immunomodulatory properties and potential clinical application. Stem Cells Cloning Adv Appl. 2014;7:53-63.

14. Marion NW, Mao JJ. Mesenchymal stem cells and tissue engineering MSCs: definition and therapeutic promise. Methods Enzym. 2006;420:339-61.

15. Raghavan N, Vignesh G, Santhosh Kumar B, Selvaraj R, Dare B. Phytochemicals: do they hold the future in stem cell differentiation. Int J Res Ayurveda Pharm. 2015;6:379-81.

16. Villareal MO, Kume S, Neffati M, Isoda H. Upregulation of Mitf by phenolic compounds-rich Cymbopogon schoenanthus treatment promotes melanogenesis in b16 melanoma cells and human epidermal melanocytes. Biomed Res Int. 2017:2017:1-11.
17. Schmidt BM, Ribnicky DM, Lipsky PE, Raskin I. Revisiting the ancient concept of botanical therapeutics. Nat Chem Biol. 2007;3:360. https://doi. org/10.1038/nchembio0707-360.

18. Ferdousi F, Sasaki K, Uchida Y, Ohkohchi N, Zheng YW, Isoda H. Exploring the potential role of rosmarinic acid in neuronal differentiation of human amnion epithelial cells by microarray gene expression profiling. Front Neurosci. 2019:13:1-10.

19. Uchida Y, Ferdousi F, Zheng Y-W, Oda T, Isoda H. Global gene expression profiling reveals isorhamnetin induces hepatic-lineage specific differentiation in human amniotic epithelial cells. Front Cell Dev Biol. 2020. https://doi.org/10.3389/fcell.2020.578036.

20. Ferdousi F, Kondo S, Sasaki K, Uchida Y, Ohkohchi N, Zheng YW, et al. Microarray analysis of verbenalin-treated human amniotic epithelial cells reveals therapeutic potential for Alzheimer's Disease. Aging (Albany NY). 2020;12:5516-38.

21. Kim HJ, Kim JS, Woo JT, Lee IS, Cha BY. Hyperpigmentation mechanism of methyl 3,5-di-caffeoylquinate through activation of p38 and MITF induction of tyrosinase. Acta Biochim Biophys Sin (Shanghai). 2015;47:548-56.

22. Kimura Y, Okuda H, Okuda T, Hatano T, Agata I, Arichi S. Studies on the activities of tannins and related compounds from medicinal plants and drugs. VI. Inhibitory effects of caffeoylquinic acids on histamine release from rat peritoneal mast cells. Chem Pharm Bull (Tokyo). 1985;33:690-6.

23. Kurata R, Yahara S, Yamakawa O, Yoshimoto M. Simple high-yield purification of 3,4,5-tri-O-caffeoylquinic acid from sweetpotato (Ipomoea batatas L.) leaf and its inhibitory effects on aldose reductase. Food Sci Technol Res. 2011;17:87-92.

24. Li HR, Habasi M, Xie LZ, Aisa HA. Effect of chlorogenic acid on melanogenesis of B16 melanoma cells. Molecules. 2014;19:12940-8.

25. Matsui T, Ebuchi S, Fujise T, Abesundara KJM, Doi S, Yamada H, et al. Strong antihyperglycemic effects of water-soluble fraction of Brazilian propolis and its bioactive constituent, 3,4,5-tri-O-caffeoylquinic acid. Biol Pharm Bull. 2004;27:1797-803.

26. Miyamae Y, Han J, Sasaki K, Terakawa M, Isoda H, Shigemori H. 3,4,5-tri-Ocaffeoylquinic acid inhibits amyloid $\beta$-mediated cellular toxicity on $\mathrm{SH}$ SY5Y cells through the upregulation of PGAM1 and G3PDH. Cytotechnology. 2011;63:191-200.

27. Yoshimoto M, Yahara S, Okuno S, Islam MS, Ishiguro K, Yamakawa O. Antimutagenicity of mono-, di-, and tricaffeoylquinic acid derivatives isolated from sweetpotato (Ipomoea batatas L.) leaf. Biosci Biotechnol Biochem. 2002:66:2336-41. https://doi.org/10.1271/bbb.66.2336.

28. Tang B, Huang Y, Yang H, Tang P, Li H. Molecular mechanism of the binding of 3,4,5-tri-O-caffeoylquinic acid to human serum albumin: saturation transfer difference NMR, multi-spectroscopy, and docking studies. J Photochem Photobiol B Biol. 2016;165:24-33. https://doi.org/10.1016/j. jphotobiol.2016.10.017.

29. Sasaki K, Davies J, Doldán NG, Arao S, Ferdousi F, Szele FG, et al. 3,4,5-Tricaffeoylquinic acid induces adult neurogenesis and improves deficit of learning and memory in aging model senescence-accelerated prone 8 mice. Aging Albany NY. 2019:11:1-22.

30. Sasaki K, Han J, Shigemori H, Isoda H. Caffeoylquinic acid induces ATP production and energy metabolism in human neurotypic SH-SY5Y cells. Nutr Aging. 2012;1:141-50.

31. Joshi SS, Tandukar B, Pan L, Huang JM, Livak F, Smith BJ, et al. CD34 defines melanocyte stem cell subpopulations with distinct regenerative properties. PLoS Genet. 2019;15:e1008034.

32. Bejaoui M, Villareal MO, Isoda H. 3,4,5-Tri-O-caffeoylquinic acid promoted hair pigmentation through $\beta$-catenin and its target genes. Front Cell Dev Biol. 2020:8:1-14.

33. Bejaoui M, Villareal MO, Isoda $\mathrm{H}$. $\beta$-catenin-mediated hair growth induction effect of 3,4,5-tri-O-caffeoylquinic acid. Aging (Albany NY). 2019;11:4216-37

34. Nishimura EK, Yoshida H, Kunisada T, Nishikawa SI. Regulation of E- and P-cadherin expression correlated with melanocyte migration and diversification. Dev Biol. 1999;215:155-66.

35. Huang DW, Sherman BT, Lempicki RA. Bioinformatics enrichment tools: paths toward the comprehensive functional analysis of large gene lists. Nucleic Acids Res. 2009;37:1-13.

36. Subramanian A, Tamayo P, Mootha VK, Mukherjee S, Ebert BL, Gillette MA, et al. Gene set enrichment analysis: a knowledge-based approach for 
interpreting genome-wide expression profiles. Proc Natl Acad Sci U S A. 2005;102:15545-50.

37. Zacariotti R, Valle R. Observation of mating in the Calico Snake Oxyrhopus petola Linnaeus, 1758. Herpetol Notes. 2010;3:139-40.

38. Caruso M, Evangelista M, Parolini O. Human term placental cells: phenotype, properties and new avenues in regenerative medicine. Int J Mol Cell Med. 2012:1:64-74

39. Gupta A, Kedige SD, Jain K. Amnion and chorion membranes: potential stem cell reservoir with wide applications in periodontics. Int J Biomater. 2015;2015:274082.

40. Jiang LW, Chen H, Lu H. Using human epithelial amnion cells in human de-epidermized dermis for skin regeneration. J Dermatol Sci. 2016;81:2634. https://doi.org/10.1016/j.jdermsci.2015.10.018.

41. Kornicka K, Kocherova I, Marycz K. The effects of chosen plant extracts and compounds on mesenchymal stem cells_-a bridge between molecular nutrition and regenerative medicine-concise review. Phyther Res. 2017;31:947-58.

42. 朋代竹内, 雅之, 野口, Takeuchi T, Noguchi M, Kawakami Y, Ohkohchi N 創薬に向けたヒ卜細胞·組織の利用 -つくばヒト組織バイオバンクセンター の取り組み-Use of human biospecimen resources for drug discoveryapproach of Tsukuba Human Tissue Biobank Center-. Rsmp. 2016;6:57-63. https://www.jstage.jst.go.jp/article/rsmp/6/1/6_57/_pdf

43. Furuya $K$, Zheng Y, of HBR for DD pdf. W, Sako D, Iwasaki K, Zheng DX, Ge JY, , et al. Enhanced hepatic differentiation in the subpopulation of human amniotic stem cells under 3D. Use Hum Biospecimen Resour Drug Discov J Stem Cells. 2019;11:705-21.

44. Niknejad H, Peirovi H, Ahmadiani A, Ghanavi J, Jorjani M. Differentiation factors that influence neuronal markers expression in vitro from human amniotic epithelial cells. Eur Cells Mater. 2010;19:22-9.

45. Panchision DM, McKay RDG. The control of neural stem cells by morphogenic signals. Curr Opin Genet Dev. 2002;12:478-87.

46. Patapoutian A, Reichardt LF. Roles of Wnt proteins in neural development and maintenance. Curr Opin Neurobiol. 2000;10:392-9.

47. Cohen MA, Itsykson P, Reubinoff BE. The role of FGF-signaling in early neural specification of human embryonic stem cells. Dev Biol. 2010;340:450-8. https://doi.org/10.1016/j.ydbio.2010.01.030.

48. Patel NS, Rhinn M, Semprich Cl, Halley PA, Dollé P, Bickmore WA, et al. FGF signalling regulates chromatin organisation during neural differentiation via mechanisms that can be uncoupled from transcription. PLoS Genet. 2013:9:7-9.

49. Racioppi C, Kamal AK, Razy-Krajka F, Gambardella G, Zanetti L, di Bernardo $D$, et al. Fibroblast growth factor signalling controls nervous system patterning and pigment cell formation in Ciona intestinalis. Nat Commun. 2014;5:4830. https://doi.org/10.1038/ncomms5830.

50. Dyer C, Blanc E, Stanley RJ, Knight RD. Dissecting the role of wnt signaling and its interactions with FGF signaling during midbrain neurogenesis. Neurogenesis. 2015;2:1-17.

51. Israsena N, Hu M, Fu W, Kan L, Kessler JA. The presence of FGF2 signaling determines whether $\beta$-catenin exerts effects on proliferation or neuronal differentiation of neural stem cells. Dev Biol. 2004;268:220-31.

52. Imayoshi I, Sakamoto M, Yamaguchi M, Mori K, Kageyama R. Essential roles of Notch signaling in maintenance of neural stem cells in developing and adult brains. J Neurosci. 2010;30:3489-98.

53. Widlund HR, Horstmann MA, Roydon Price E, Cui J, Lessnick SL, Wu M, et al. $\beta$-Catenin-induced melanoma growth requires the downstream target Microphthalmia-associated transcription factor. J Cell Biol. 2002;158:1079-87.
54. Schepsky A, Bruser K, Gunnarsson GJ, Goodall J, Hallsson JH, Goding CR, et al. The microphthalmia-associated transcription factor mitf interacts with -catenin to determine target gene expression. Mol Cell Biol. 2006;26:8914-27.

55. Takeo M, Lee W, Rabbani P, Sun Q, Hu H, Lim CH, et al. EdnrB governs regenerative response of melanocyte stem cells by crosstalk with Wnt signaling. Cell Rep. 2016;15:1291-302. https://doi.org/10.1016/j.celre p.2016.04.006.

56. Weiss RS, Leder P, Vaziri C. Critical role for mouse Hus 1 in an S-Phase DNA damage cell cycle checkpoint. Mol Cell Biol. 2003;23:791-803.

57. Ohnuma SI, Harris WA. Neurogenesis and the cell cycle. Neuron. 2003;40:199-208.

58. Pierfelice T, Alberi L, Gaiano N. Notch in the vertebrate nervous system: an old dog with new tricks. Neuron. 2011;69:840-55. https://doi. org/10.1016/j.neuron.2011.02.031.

59. Mehler MF, Mabie PC, Zhu G, Gokhan S, Kessler JA. Developmental changes in progenitor cell responsiveness to bone morphogenetic proteins differentially modulate progressive CNS lineage fate. Dev Neurosci. 2000;22:74-85. https://doi.org/10.1159/000017429.

60. Ten Dijke P, Hill CS. New insights into TGF- $\beta$-Smad signalling. Trends Biochem Sci. 2004;29:265-73.

61. Hou L, Panthier JJ, Arnheiter H. Signaling and transcriptional regulation in the neural crest-derived melanocyte lineage: interactions between KIT and MITF. Development. 2000;127:5379-89.

62. D'Mello SAN, Finlay GJ, Baguley BC, Askarian-Amiri ME. Signaling pathways in melanogenesis. Int J Mol Sci. 2016;17:1-18.

63. Leclerc EA, Hucheng A, Kezic S, Serre G, Jonca N. Mice deficient for the epidermal dermokine $\beta$ and $\gamma$ isoforms display transient cornification defects. J Cell Sci. 2014;127:2862-72.

64. Wu Y, Sheng W, Chen L, Dong H, Lee V, Lu F, et al. Versican V1 isoform induces neuronal differentiation and promotes neurite outgrowth. Mol Biol Cell. 2004;15:2093-104.

65. Engeland K. Cell cycle arrest through indirect transcriptional repression by p53: I have a DREAM. Cell Death Differ. 2018;25:114-32. https://doi. org/10.1038/cdd.2017.172.

66. Beck HN, Drahushuk K, Jacoby DB, Higgins D, Lein PJ. Bone morphogenetic protein-5 (BMP-5) promotes dendritic growth in cultured sympathetic neurons. BMC Neurosci. 2001;2:12. https://doi. org/10.1186/1471-2202-2-12.

67. Shih H-Y, Hsu S-Y, Ouyang P, Lin S-J, Chou T-Y, Chiang M-C, et al. Bmp5 regulates neural crest cell survival and proliferation via two different signaling pathways. Stem Cells. 2017;35:1003-14. https://doi.org/10.1002/ stem.2533.

68. Rubio N, Cerciat M, Unkila M, Garcia-Segura LM, Arevalo MA. An in vitro experimental model of neuroinflammation: The induction of interleukin-6 in murine astrocytes infected with Theiler's murine encephalomyelitis virus, and its inhibition by oestrogenic receptor modulators. Immunology. 2011;133:360-9.

69. Benihoud K, Esselin S, Descamps D, Jullienne B, Salone B, Bobé P, et al. Respective roles of TNF- $a$ and IL- 6 in the immune response-elicited by adenovirus-mediated gene transfer in mice. Gene Ther. 2007;14:533-44. https://doi.org/10.1038/sj.gt.3302885.

\section{Publisher's Note}

Springer Nature remains neutral with regard to jurisdictional claims in published maps and institutional affiliations. 